\title{
LOSS OF INFORMATION DURING DESIGN \& CONSTRUCTION FOR HIGHWAYS ASSET MANAGEMENT: A GEOBIM PERSPECTIVE
}

\author{
G. S. Floros ${ }^{* 1}$ and C. Ellul ${ }^{1}$ \\ ${ }^{1}$ Dept. of Civil, Environmental \& Geomatics Engineering, UCL, Gower Street, London, WC1E 6BT, UK - \\ george.floros.17@ucl.ac.uk; c.ellul@ucl.ac.uk
}

KEY WORDS: BIM, GIS, GeoBIM, IFC, Asset Information Model, 3D, Infrastructure, Information loss

\begin{abstract}
:
Modern cities will have a catalytic role in regulating global economic growth and development, highlighting their role as cen ters of economic activity. With urbanisation being a consequence of that, the built environment is pressured to withstand the rapid increase in demand of buildings as well as safe, resilient and sustainable transportation infrastructure. Transportation Infrastructure has a unique characteristic: it is interconnected and thus, it is essential for the stakeholders to be able to capture, analyse and visualise these interlinked relationships efficiently and effectively. This requirement is addressed by an Asset Information Management System (AIMS) which enables the capture of such information from the early stages of a transport infrastructure construction project. Building Information Modelling (BIM) and Geographic Information Science/Systems (GIS) are two domains which facilitate the authoring, management and exchange of asset information by providing the location underpinning, both in the short term and through the very long lifespan of the infrastructure. These systems are not interoperable by nature, with extensive Extract/Transform/Load procedures required when developing an integrated location-based Asset Management system, with consequent loss of information. The purpose of this paper is to provide an insight regarding the information lifecycle during Design and Construction on a Highways Project, focusing on identifying the stages in which loss of information can impact decision-making during operational Asset Management: (i) 3D Model to IFC, (ii) IFC to AIM and (iii) IFC to 3DGIS for AIM. The discussion highlights the significance of custom property sets and classification systems to bridge the different data structures as well as the power of 3D in visualizing Asset Information, with future work focusing on the potential of early BIM-GIS integration for operational AM.
\end{abstract}

\section{INTRODUCTION}

Transportation Infrastructure has a vital role in the social prosperity, economic growth and environmental sustainability of a country (Liu et al., 2019), with the transportation network often being one of the largest and most valuable public infrastructure assets of a country (Sinha et al., 2017; Shah et al., 2017). The expectations from the public are high; ever evolving requirements around safety, reduced journey times and a demand for a well-maintained transportation network for example. National and local authorities aim to address these requirements under onerous financial requirements with the goal being to achieve maximized value from their assets with less resources (Shah et al., 2017).

Asset Management (AM) is fundamental to this task, realising and extracting the value of what constitutes an Asset to the organisation with the Asset Management Plan (AMP) being the imperative tool to help the organisation reach its objectives (ISO 55000, 2014). Organizational change and fit for purpose use of the available technology, are fundamental to a successful AMP (Jafari, 2016) with software and data forming a key part of the latter (Shah et al., 2017).

From a data perspective, these two interlinked challenges are underpinned by the implementation of Asset Information Management Systems (AIMS), with the common underlying element of any proposition being efficient and effective utilisation of data (Yang et al., 2019). Location-enabled data is of fundamental importance to Infrastructure Asset Management, not only to address issues relating to condition assessment, maintenance scheduling, health and safety, and strategic decision making (Garramone et al., 2020) but also to enable democratization of information via the power of 3D Visualisation (Liu et al., 2021).

\subsection{Location Data for AIMS}

In the lifecycle of infrastructure, two broad phases can be identified - Design \& Construction and Operation \& Maintenance. In the UK a key component of any major construction project is the Asset Information Requirements. These form the foundation for the information required for handover between D\&C and O\&M, to enable an organisation to maintain its assets during the operational stages of its lifecycle. Location intelligence and the use of Geographic Information Science/Systems (GIS) are typically incorporated as part of the contractual requirements for AIM.

In parallel with this, the UK BIM Mandate requires the use of Building Information Modelling for major infrastructure construction projects. BIM is very information rich, and this location data is expensive to capture, update and maintain, particularly over the long term where format and storage and software changes need to be addressed. However, although such location-enabled information is fundamental to infrastructure asset $\mathrm{O} \& \mathrm{M}$, much of this construction information is currently discarded, with a small fraction handed over to $\mathrm{O} \& \mathrm{M}$.

It is hypothesized that this discarded information - structural detail, construction material detail and more - may also be relevant for long term asset operation and maintenance. Provided it can be integrated into the AIM in a suitable manner and the cost of long-term data curation can be justified, making use of such data could save extensive future data capture costs, and also provide hidden structural detail that can't be captured retrospectively. However, while it might be considered ideal never to throw any information away, in reality it is important to understand, justify and evaluate the cost/benefit issues, relating to both the decision to maintain information long term and that to discard it. 


\subsection{Purpose \& Research Question}

This paper focuses on an important component of this wider information management challenge: the understanding, and documentation of information losses when comparing the subset of information required by the AIR to the wealth of construction data available from BIM. Such losses are caused both by the AIR specification itself, but also by the challenges encountered when converting BIM to 2D or 3D GIS for integration with AIMS in one system. BIM and GIS are not interoperable by nature (Noardo et al., 2020) and AIMs adds a third domain into this loss of information challenge. Working within a transportation infrastructure context, the proposed method documents the loss of information at three different levels: (i) BIM Authoring Tools to IFC, (ii) IFC to AIM and (iii) IFC to 3D/2D GIS for AIM. The reason for investigating the IFC-GIS-AIM route is the specifications of the AIRs which require the delivery of GIS datasets with this work exploring the potential of GeoBIM producing this information, rather than recreating using laborious and time consuming digitisation processes. Therefore, the Research Question this paper aims to address is:

\section{"What are the information losses when integrating BIM into 3D GIS to provide location underpinning for Asset Management?"}

This research is part of ongoing work investigating the information lifecycle in Transportation Infrastructure projects, and particularly Highways and Rail. The outcomes provide Asset Operators with a clearer picture of information available to them, to allow them to make an informed decision as to whether to invest time, effort and finances in improving existing integration processes.

\section{LITERATURE REVIEW AND PREVIOUS WORK}

\subsection{GIS-BIM Integration for Asset Management}

2.1.1 Potential of GeoBIM for AM: The geospatial community has identified Asset Management as a principal application field that can benefit from GIS-BIM integration (Ellul et al., 2020). Garramone et al. (2020) propose multiple services within AM that may benefit from GeoBIM such as Condition Inspection \& Monitoring, Facility Management and Risk Management. However, there are fundamental issues to be addressed focusing on interoperability, data structures and understanding of the GeoBIM concept.

Boyes et al. (2017) investigate the integration of GIS-BIM for asset management in the Crossrail infrastructure project in UK, summarizing the key findings into: (i) geometric differentiations between BIM and GIS and (ii) decision making during asset tagging in relation to space reservations within the models. Park et al. (2014) explore BIM-GIS integration to estimate the project cost of a road infrastructure project, including operational and maintenance. A system is proposed, which provides a 3D visualisation of the project simulating different scenarios by linking information related to quantities, earthworks, land acquisition costs and $\mathrm{O} \& \mathrm{M}$ costs, offering to the stakeholders more informed decision making with regards to the optimal scenario.

Farghaly et al. (2017) investigate a big data system architecture for Asset Management utilizing BIM. In this research work, BIM requirements are identified, highlighting the stage: "data to information" critical, as the collected data need to be properly stored, managed and exchanged, but also enriched by integrating multiple data sources and primarily GIS data. Kang and Hong, (2015) propose a BIM-GIS solution for facility management in order to address the interoperability challenges of the supported data formats. Utilizing an ETL (Extract-Transform-Load) process they create a workflow that facilitates a unidirectional conversion from BIM (IFC) to 3DGIS (CityGML) and links the generated models with data sources that contain information relevant to facility management. In this particular case study, GIS is utilized as the primary client and visualisation tool to store and exchange this information in $3 \mathrm{D}$ and provide access to a detailed BIM Viewer.

2.1.2 Integration Challenges: Extensive research efforts are directed towards BIM-GIS interoperability. The "GeoBIM Benchmark 2019" (Noardo et al. 2020) initiative commenced in 2017 and concluded in 2019, approaches BIM-GIS integration from two perspectives: (i) technical challenges in data interoperability and (ii) understanding requirements and use cases between the BIM and GEO domains (Ellul et al., 2020). Biljecki and Tauscher (2019) summarise in detail the most common errors noted in the IFC-CityGML conversion, focusing particularly on geometry, semantics and topology.

With regards to geometry, the major challenges involve the conversion of curved surfaces, missing geometric features and poorly geolocated geometries due to the use of local coordinate systems (Biljecki and Tauscher, 2019; Noardo et al., 2019). The "GeoBIM benchmark 2019" (Noardo et al., 2019) investigates the conversion from IFC to 3DGIS, using a variety of 3D models (Noardo et al., 2019) which represent different types of buildings.

One of the most important aspects of BIM-GIS integration has been the loss of semantic information during the conversion process. The 3D Models produced by BIM authoring tools, typically are more enriched in terms of representing geometric details, which consequently leads to increased semantic incorporation and notable differences in the semantic classification compared to a 3DGIS model (Biljecki and Tauscher, 2019). Therefore, the semantic differences between BIM and GIS Standards leads to features being either mismapped or classified within non-relevant entities (Floros et al., 2020).

Arroyo Ohori et al. (2017) focus on the topological challenges that arise during an IFC to CityGML conversion, which are also interconnected with the geometric issues such as self-intersecting polygons and non-planar surfaces. On top of that, converting adjacent surfaces or surfaces that share the same characteristics from IFC to 3DGIS introduces topological inconsistencies, as the modelling is facilitated using the "Xlinks" functionality (Biljecki et al., 2019; Floros et al., 2018).

With specific focus on infrastructure, preliminary work relating to understanding the Asset Information Systems and Requirements for Highways and their relation to openBIM Standards such as IFC, has highlighted integration challenges at a data level (Floros et al. 2019), while the maturity of model information from Design to Construction to Handover for Rail Infrastructure creates significant barriers in the downstream BIM-GIS-Asset Management interoperability for O \& M (Floros et al., 2020).

2.1.3 ETL as a Conversion Tool: One of the most used approaches when converting from BIM to GIS and particularly IFC to CityGML is the use of Extract-Transform-Load (ETL) process. ETL offers the capability of breaking down - or extracting- a model into its consisting elements (IfcWall, IfcSlab, 
IfcPile) so the user is able to manipulate the data within a graphical interface by using "Transformers" that perform specific actions, such as geometry conversion from solid to b-rep. The modified dataset is written to the desired format which can then be viewed and interrogated via relevant data viewers. The ETL process typically is semi-automated (Liu et al., 2017) providing significant flexibility tailored to different model requirements and is able to manipulate and retain semantic information (Floros et al., 2018).

There are however considerable drawbacks when it comes to the implementation of the ETL process to convert IFC models to 3DGIS. Firstly, the configuration of the process is heavily dependent on the developer's interpretation of the model elements and the mapping to the corresponding 3DGIS entities. Secondly, depending on the size and elements of the model, it can be performance intensive. Additionally, it is heavily dependent on the semantic enrichment of the data source which leads to the requirement of recreating parts of the process to suit the needs of models with different structure ( Noardo et al., 2019; Liu et al., 2017; Floros et al., 2020).

\subsection{Standards, Processes \& Classification Systems}

2.2.1 BS EN ISO 19650 AND PAS 1192: BS EN ISO 19650:1 and BS EN ISO 19650:2 are the latest Standards on systemic Information Management as well as the Standards which the BIM process needs to adhere to, during the technical lifecycle with the development of the BIM Execution Plan. The ISO 19650 series are closely aligned withthe British set of Standards PAS 1192, however they provide an international outreach (NBS, 2021).

The British Set of Standards PAS 1192 series, specifies the Information Models to be developed during the lifecycle, starting with the Project Information Model (PIM), which consists of Graphical Information, Non-Graphical Information and Documentation and eventually evolves to the Asset Information Model (AIM) post-handover, which is used by the organisation to operate and maintain its assets (PAS 1192-3, 2013).

2.2.2 IFC: IFC is an OpenBIM Standard developed by buildingSMART (buildingSMART, 2021) focusing mainly on Buildings with the inclusion of Infrastructure objects such as Bridges being currently under development.

2.2.3 Uniclass 2015: Uniclass2015 is a classification system of the built environment for the AECOO industry, with multiple levels of granularity, varying from the description of the generic asset class (Highways, Bridge) up to specific asset elements (Beams, Handrail) (NBS, 2021). Uniclass2015 is introduced typically during the Design stage and is used for multiple purposes including Estimating, CAD Drawing and Layer specification (Gelder, 2015).

\section{DATA}

\subsection{Data Provider}

The data for this research is provided by the Skanska ${ }^{1} \mathrm{UK}$ Infrastructure BIM team working on the Regional Delivery Partnership (RDP) scheme on behalf of Highways England $(\mathrm{HE})^{2}$. Skanska UK-Infrastructure is the Main Contractor, working with Mott MacDonald as the Designer to deliver the Design and Construction of the above scheme.

\subsection{Datasets}

The main datasets utilised in this work are: (i) a 3D Model of a Bridge for Highways and (ii) the Asset Data Management Manual of Highways England which defines the scope of the AIMS and its Asset Information Requirements.

3.2.1 3D Model - Bridge: The dataset that the proposed method is developed upon is a Bridge in the stage of Scheme Design, which has been created within Autodesk Revit and exported to IFC 2X3 Version (fig.1). This Bridge is an example of the Structures involved during the Design and Construction of Highways and it has been selected mainly for two reasons: firstly, it has one of the most asset information rich semantic structures within the ADMM and secondly it is an Infrastructure Asset that can be used to support other types of infrastructure such as Rail, which creates opportunities for the scaling implementation of the proposed method across the two infrastructure sectors (Highways and Rail). The coordinate system used for the design of the Model is HE Local Grid reprojected to British National Grid once transferred to GIS.

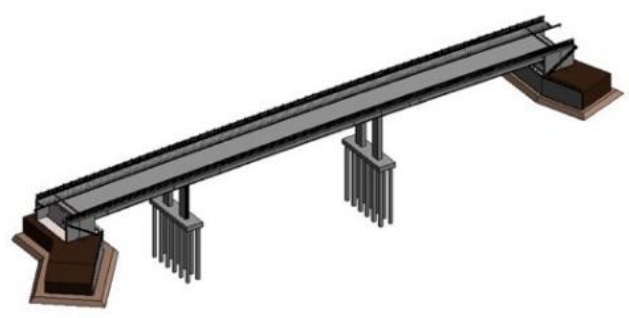

Figure 1. IFC Bridge.

3.2.2 Asset Data Management Manual (ADMM): The AIR in this case is the ADMM for HE (ADMM, 2021) consists of four parts: (i) Data Principles and Governance, (ii) Requirements and Additional Information, (iii) Data Dictionary and (iv) Asset Reference Catalogue. In this work, the first $\left(1^{\text {st }}\right)$ part sets the tone in understanding HEs AM Vision focusing on linking all Asset Information within a single system so they can operate their Assets efficiently and effectively. The Data Dictionary, alongside the Asset Requirements is the data-oriented version of the $\mathrm{ADMM}$ and the one that is being utilised in this paper. The Data Dictionary contains information about the Asset Classes, Asset Names, Asset Attributes as well as the linking to Uniclass2015. The Data dictionary is provided as an extracted Excel spreadsheet that describes the structure of HE's AIMS. The Asset Class describes generic classes such as Structures, Pavement or Geotechnical, with the Asset Name providing the granular detail to a Bridge, a Retaining Wall or a Gantry. Attribute Names include the additional information needed to describe the condition of the Asset. Figure 2 provides an example of the ADMM extract in a UML representation.

\subsection{Software Tools}

Feature Manipulation Engine 2021 (FME) is the ExtractTransform-Load (ETL) software tool that is used to process and transform the 3D Model and facilitate the mapping between the 3D Model and the Asset Data Management Manual (ADMM).

\footnotetext{
${ }^{1}$ Skanska is a global Construction Company operating in the UK

${ }^{2}$ Highways England is a public body operating and maintaining Highways Assets in the UK
} 
Autodesk Revit 2020 is the BIM Authoring tool of the 3D Model, while the GIS outputs are visualised in ESRI ArcGIS Pro 2.7.2.

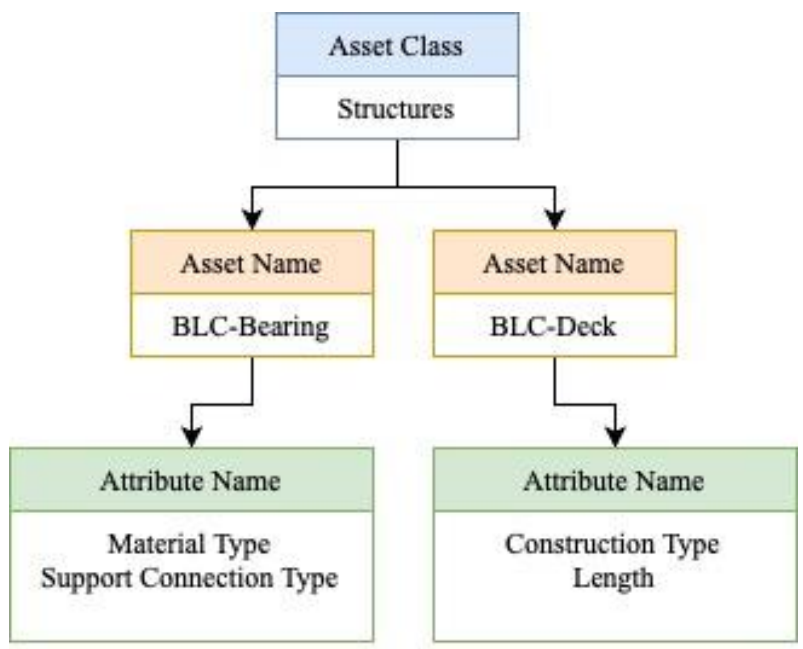

Figure 2. UML Representation of the ADMM-An example.

\section{METHOD}

The proposed method of this work consists of 5 stages as illustrated in figure 3 :

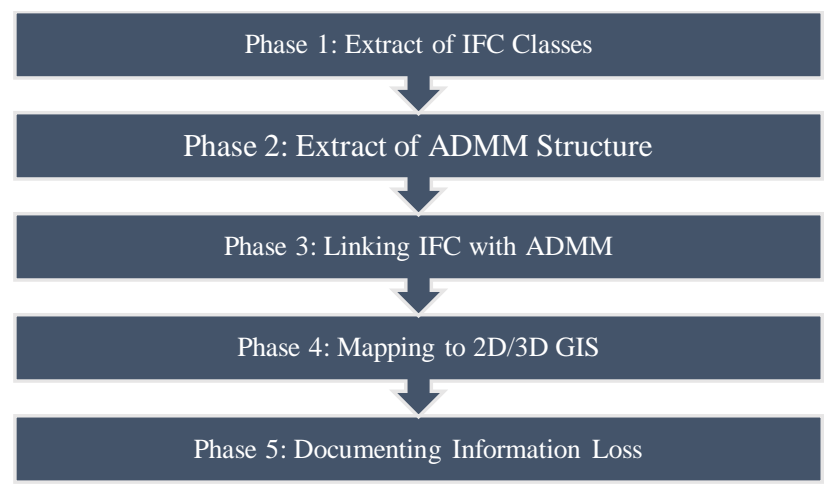

Figure 3. The proposed method.

\subsection{Phase 1: Extract of IFC Classes}

The IFC model of the Bridge is produced as an export from Autodesk Revit and then it is being imported in Feature Manipulation Engine (FME) in order to extract its individual classes, as summarised in table 1:

\begin{tabular}{|l|l|l|}
\hline IfcBeam & IfcBuildingElementProxy & IfcColumn \\
\hline IfcRailing & IfcSlab & IfcStair \\
\hline IfcWall & IfcWallStandardCase & IfcPropertySet \\
\hline
\end{tabular}

Table 1. Classes of IFC Bridge.

As described in Section 3, the model contains custom Property Sets that are not being natively included within IFC. These Property Sets include information generated during Design and Construction such as Material, Length, and Volume among others. Therefore, during the extract process, the custom property sets are linked with the relevant classes using a "parent-child" id relationship.

\subsection{Extract of the ADMM Structure}

The ADMM Extract is being processed within FME in order to group based on Asset Class $=$ 'Structures' and Asset Name $=$
'BLC' which stands for Bridge and Large Culvert. For each Asset Name, the Uniclass 2015 and Attribute Names are extracted in a tabular format pending further processing.

\subsection{Linking IFC with ADMM}

The next step in the process links the ADMM structure with the IFC schema. The link is facilitated by using Uniclass 2015 as the common join attribute between the two schemas within FME.

\subsection{Mapping to 2D/3DGIS}

Next, follows the conversion from a 3D Model in IFC to a 2D and 3DGIS Model which incorporates the Asset Information Requirements as a data schema, whilst also logs the transition and potential loss of information from IFC to GIS. To address the interoperability between BIM and GIS, the workflow within FME performs the conversion at two stages: (i) geometric conversion and (ii) semantic mapping. The Geometric conversion involves the transition of Constructive Solid Geometry (CSG) Solid Geometry to a b-rep Geometry in GIS, while the Semantic Mapping maintains the semantic structure of the IFC, enriched by the ADMM. Figure 4 presents an example of the 3DGIS output and its semantic structure.

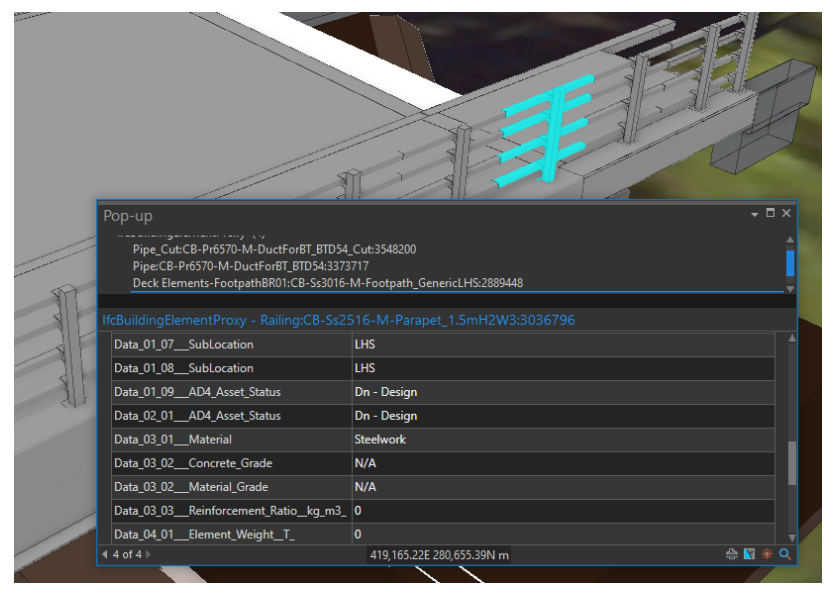

Figure 4. Semantic Output in 3DGIS.

\subsection{Documenting Information Loss}

The final step of the process involves the documentation of information loss both for 3D and 2D GIS outputs focusing on two stages: geometry and semantics (table 2). The set of criteria selected captures the geometry type of the features (i.e., Polyhedras, Solids, Polygons), as well as the Number of features before and after conversion for each IFC Class. This allows a high-level to ensure that the input features match the produced output. The second set of criteria emphasizes on capturing the property sets that have been dropped during the conversion to GIS. These property sets (i.e., Concrete Grade, Location) are stored in a different table to facilitate the semantic comparison with the AIRs. Lastly, information loss with regards to the $3^{\text {rd }}$ Dimension (i.e., Height, Volume) is parsed to the 2D GIS output as an additional attribute.

\begin{tabular}{|l|c|c|c|}
\hline Criteria & Geometry & Semantics & Dimension \\
\hline $\begin{array}{l}\text { Geometry Type } \\
\text { (before and after } \\
\text { conversion) }\end{array}$ & $\mathrm{X}$ & & 3D, 2D \\
\hline $\begin{array}{l}\text { Number of Features } \\
\text { (before and after } \\
\text { conversion) }\end{array}$ & $\mathrm{X}$ & & 3D, 2D \\
\hline
\end{tabular}




\begin{tabular}{|l|l|l|l|}
\hline $\begin{array}{l}\text { Number and Type of } \\
\text { Semantics dropped }\end{array}$ & & $\mathrm{X}$ & 3D, 2D \\
\hline $\begin{array}{l}\mathrm{Z} \text { Value } \\
\text { Maintenance }\end{array}$ & $\mathrm{X}$ & $\mathrm{X}$ & 2D \\
\hline
\end{tabular}

Table 2. Metadata for Information Loss.

\section{RESULTS}

Figure 5 summarises the different Object Types that are contained within each IFC Class. IfcBuildingElementProxy stores the most Object Types, followed by IfcSlab, both consisting of elements that differ considerably in nature leading to a misinforming mapping for the end user.

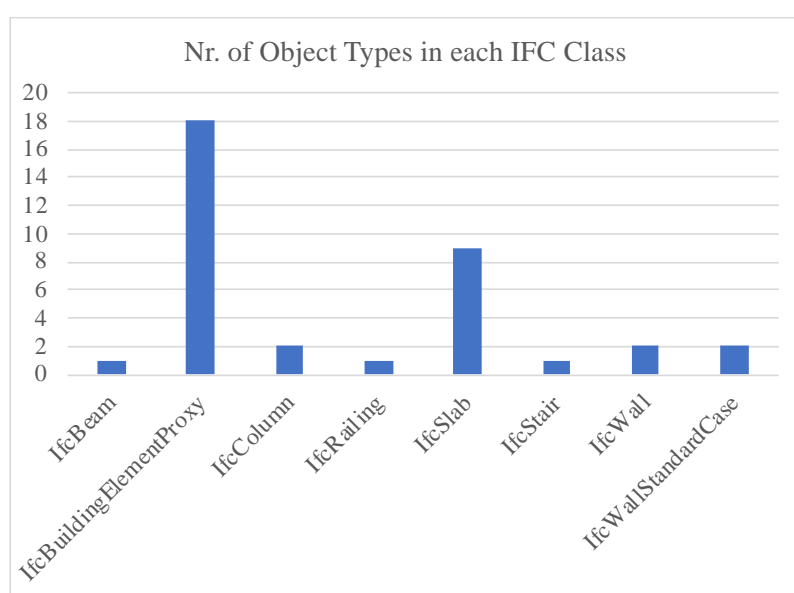

Figure 4. Object Types per IFC Class.

This highlights the fact that there is information loss from a mapping perspective from the very early stages of the process, as the generation of the IFC Model is happening utilising built-in functionality of the software tools.

Figures 6 and 7 present the 2D and 3D GIS outputs respectively. From a visualisation perspective, figure 8 contains 3D geometric information which aims to aid the decision-making of the stakeholders with the increased Level of Detail, compared to figure which presents a flattened 2D Version of the same model.

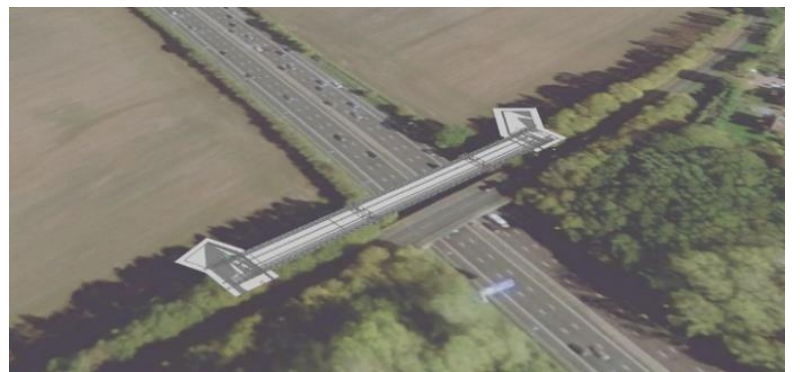

Figure 5. GIS Output in 2D.

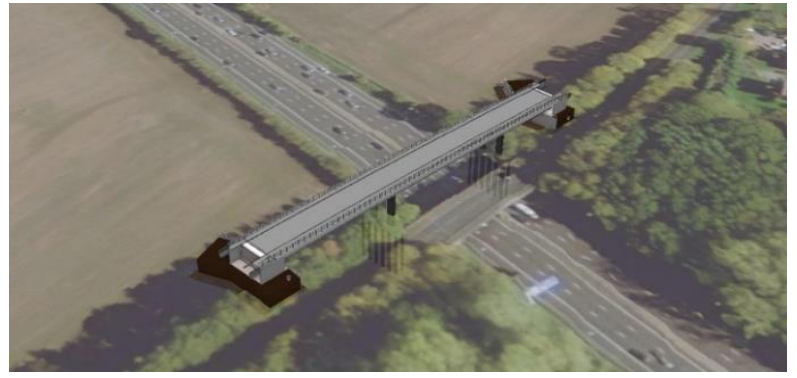

Figure 6. GIS Output in 3D.
To further illustrate how visualisation can potentially impact decision making, figure 8 focuses on highlighting an element that is not easily recognisable, a stiffener plate in $3 \mathrm{D}$ view, as the same object in a 2D GIS does not provide an identifiable geometric visualisation.

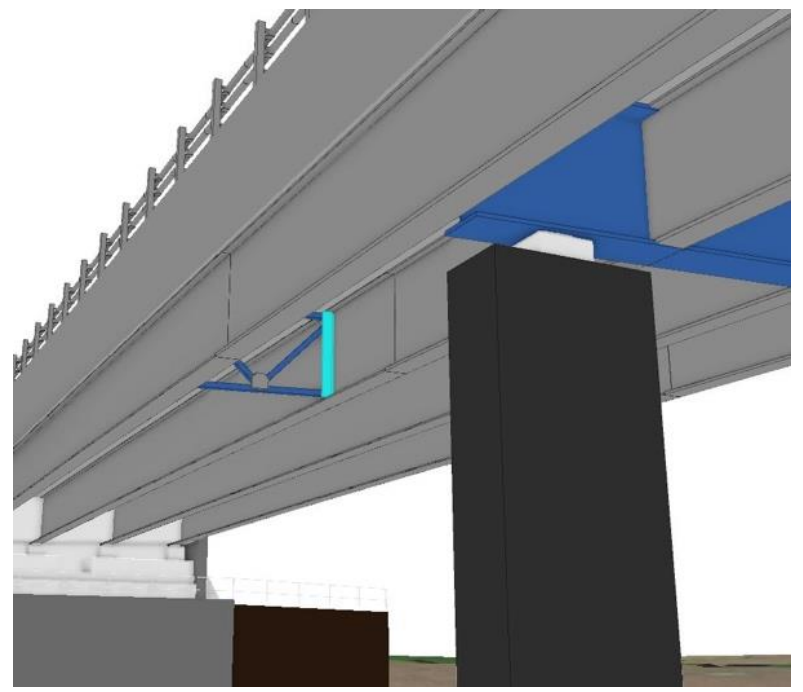

Figure 7. 3D View of a Stiffener Plate.

Table 3 summarises the results on identifying information loss across three stages in the information lifecycle during Design and Construction.

\begin{tabular}{|l|l|l|}
\hline Stages & Geometry & Semantics \\
\hline 3D Model to & $\begin{array}{l}\text { Loss of } \\
\text { Geometry has } \\
\text { not been } \\
\text { detected on the } \\
\text { current model }\end{array}$ & $\begin{array}{l}\text { IfcBuildingElementProxy } \\
\text { and IfcSlab consist of } \\
\text { different Object Types } \\
\text { Custom Property Sets are } \\
\text { not natively read within } \\
\text { the IFC Schema }\end{array}$ \\
\hline IFC to AIM & $\begin{array}{l}\text { Loss of } \\
\text { Geometry may } \\
\text { occur when } \\
\text { Uniclass2015 } \\
\text { values do not } \\
\text { match }\end{array}$ & $\begin{array}{l}\text { Significant drop in the } \\
\text { required Asset } \\
\text { the custom Property Sets }\end{array}$ \\
\hline $\begin{array}{l}\text { IFC to GIS } \\
\text { for AIM }\end{array}$ & $\begin{array}{l}\text { Loss of 3D } \\
\text { the production } \\
\text { of 2D Datasets } \\
\text { (Polyhedras -> } \\
\text { Polygons) }\end{array}$ & $\begin{array}{l}\text { 3D Information is stored } \\
\text { as attribute within a 2D } \\
\text { Geometry (i.e., volume) }\end{array}$ \\
\hline
\end{tabular}

Table 3. Summary Table of Information Loss.

Figure 9 presents a UML diagram which highlights the association at a conceptual level between the IFC Schema and the Asset Information Requirements. The UML diagram describes the available IFC Classes and the Object Types they enclose as well as their relationship with the relevant Asset Names as per the ADMM (in blue). The connection of the two is facilitated using Uniclass 2015 where available, as there are Instances such as the IfcRailing in which the Uniclass2015 value as created during Design does not match the Uniclass2015 value according to the ADMM. This highlight a second stage on which information loss is noted between conversions at a semantic level. 


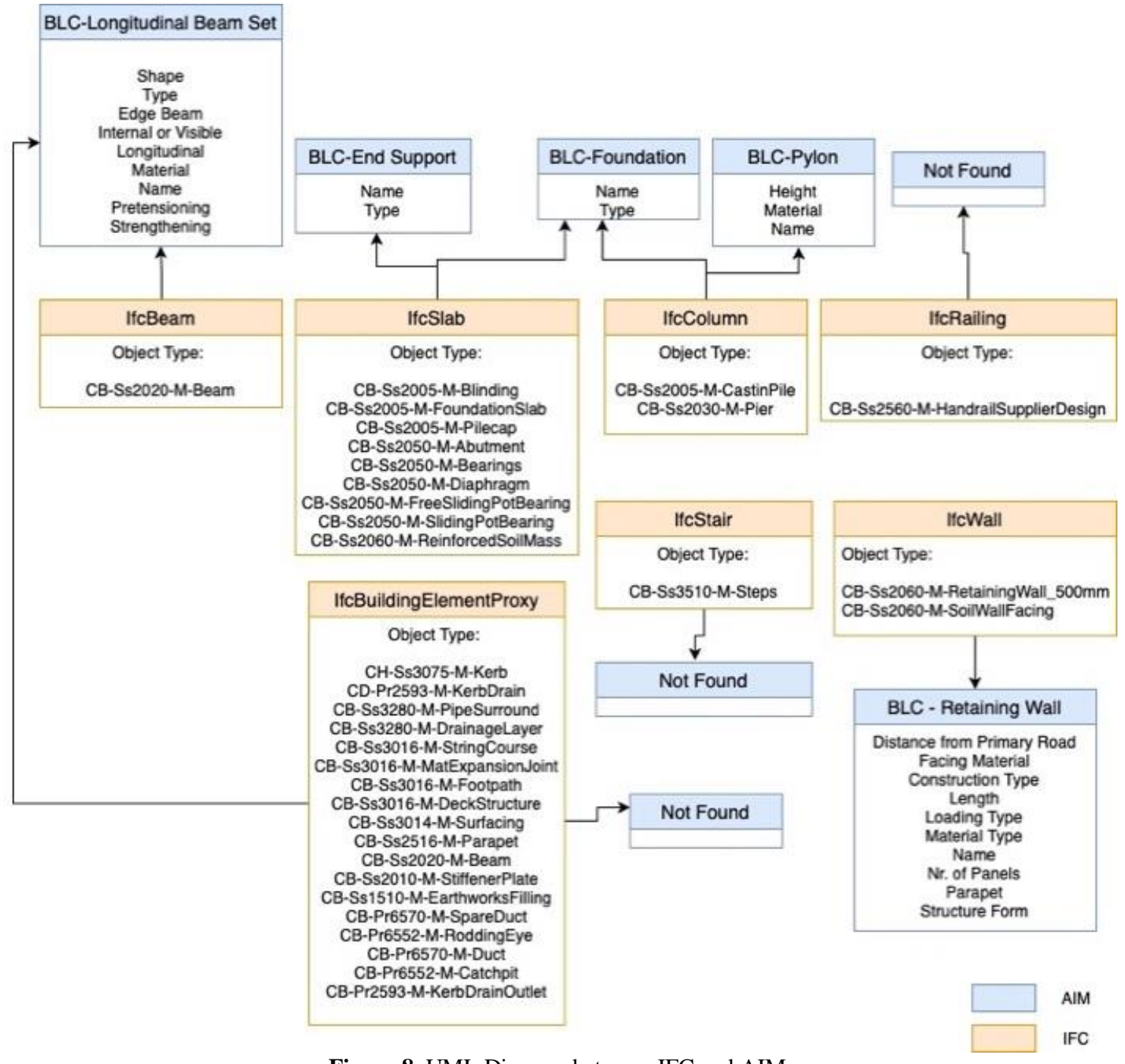

Figure 8. UML Diagram between IFC and AIM.

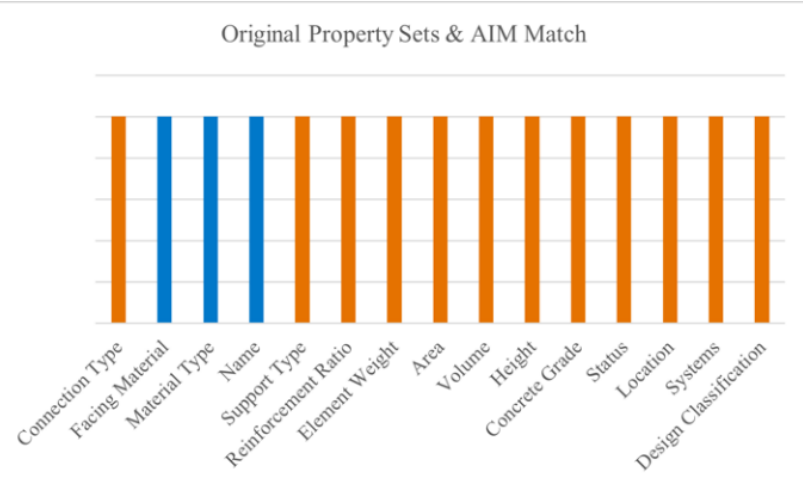

Figure 10. Semantic Comparison of Information Loss (property sets transferred to AIM are highlighted in blue).

With regards to the Number of Geometry Features in the original IFC Model as well as in the 2D and 3D GIS outputs, all geometric features are being maintained during the conversion across all classes. The Geometry Type has changed from CSG Solid to a Polyhedral surface for 3D and a Polygon for 2D. Figure 10 presents a semantic comparison between the property sets that have been dropped (orange colour) with the AIM requirements (blue colour) as per the ADMM for the IFC Slab.

\section{DISCUSSION}

This paper investigates the information loss when transitioning from construction-driven BIM to a 2D/3D GIS underpinned AIM, extending ongoing work with regards to capturing data requirements and understanding the potential of GeoBIM during Operation \& Maintenance for Transportation Infrastructure, in particular Highways and Rail. The conversion to GIS is contractually driven, but also adopts the philosophy of generating the information once (in BIM in this scenario) and use it multiple times with data longevity being considered too. It focusses on a bridge as a Highways Asset during the stage of scheme design and examines the different stages of the asset's information lifecycle until it reaches the handover stage, addressing the question:

"What are the information losses when integrating BIM into 3D GIS to provide location underpinning for Asset Management?"

Current work addresses this challenge by presenting an approach to integrate BIM, GIS and AIM. Exploring the transition of information at a conceptual level from proprietary data formats to OpenBIM Standards such as Industry Foundation Classes 
(IFC), their relationship to an AIM as well as the generation of the required GIS output, both in 3D and 2D aim to provide an insight on the technical and non-technical challenges that prevent the uptake of GeoBIM

A method is proposed to break down the structure of an IFC Model and link it with the structure of the prospective Asset Information Model in an effort to streamline the flow of information between the two. This method highlights the importance of custom Property Sets to address the limitations of the IFC's schema for Infrastructure and enable the mapping with other systems. In this work, the Uniclass2015 classification system is the common attribute which is used to join the IFC schema with the Asset Information Model. The method continues with the generation of the asset as a GIS output, both in 3D and 2D in an effort to understand potential benefits of 3D Visualisation and increased Level of Detail. The method concludes by proposing a set of metadata according to the validation process as implemented in the project to be captured during the conversion process. This aids the documentation and evaluation of potential loss of information that can impact decision-making for Asset Management. As for limitations of the study, the proposed set is focusing on the geometry and semantics, without taking into consideration information loss that may occur from texture loss or topological errors, therefore the proposed property sets is not an exhaustive list of capturing information loss. Additionally, this study is based upon the particular design guidelines of one Contractor, leaving room for enriching the results as part of future work.

To answer the research question, it is essential to understand the type of information that is being lost and propose a scalable methodology that can capture this information. The benefit of the current method is its automation during the conversion allowing the batch processing of multiple models. As demonstrated in Section 5, there are three stages during which the loss of information is encountered and to a considerable extent this is dependent on the Level of Model Information and the custom property sets that enrich it, creating significant challenges to a unified standardised method. However, the use of Uniclass 2015 is promising as it can provide a unified approach when describing an asset.

This paper considers the ADMM as the guiding document on identifying the Asset Information Requirements for Highways Assets. Three stages during the information lifecycle within Design-Construction and Handover are identified:

- 3D Model to IFC: The export of a 3D Model to IFC introduces mis mapping of information which complicates the integration efforts with the Asset Information Model or 3DGIS Standards to be used for Operation \& Maintenance.

- IFC to AIM: The main link between the IFC and AIM is Uniclass2015. However, the classification values have been specified by different parties: the Contractor assigns the values during the generation of the 3D Model, while the Owner/Operator is responsible for the values within the AIM. Thus, there are instances on which different Uniclass 2015 are assigned to describe the same Asset, which may lead in poor mis mapping when transferring information from one system to another.

- $\quad$ IFC to 2D GIS for AIM: As a 2D GIS dataset is the desired output to facilitate the delivery of Asset Information the loss of information is focused on the drop of the 3D Geometry and the conversion to a polygon representation of the Asset.
The custom property sets are maintained during the conversion process before being mapped to the ADMM requirements, whilst information that describe geometric characteristics such as Volume is incorporated as an attribute.

- $\quad$ IFC to 3DGIS for AIM: The 3D GIS dataset is compared with the respective 2D GIS output to identify information loss and discuss the potential of GeoBIM in AM. The geometry is converted to a polyhedral representation, whilst the semantic structure follows the AIM specifications.

To validate the accuracy of the conversion and the maintenance of the information the following rules been applied during the ETL conversion process and they focus on: (i) number of features before and after conversion, (ii) geometry type and (iii) semantic coherence to the AIM specification. Whilst the technical challenges of the BIM to GIS are not fully resolved yet, in this work the stages of producing the IFC model, as well as the mapping to AIM are considered more impactful to the downstream BIM-GIS interoperability for O \& M.

\section{CONCLUSIONS \& FUTURE RESEARCH WORK}

In the United Kingdom, it is estimated that interoperable, accessible and reliable location data can be worth over GBP 4 billion per year for the infrastructure sector, contributing towards the development of a location enabled Information Model that will improve the resilience of the UK's Infrastructure (UK Geospatial Strategy 2020-2025). Two key sources are BIM and GIS, with their integration being instrumental into providing the multi-scale location framework which is required to underpin all national digital twins.

Lifecycle Information Management aims to provide a seamless flow of data across the technical lifecycle, delivering the "right" piece of information to the "right" person at the right time with minimum cost. GeoBIM has a role in this process, with data integration serving the purpose of collecting once and using multiple times. There are however challenges around system interoperability and awareness of the GeoBIM potential that need to be addressed. Addressing the contractual requirements in an effective and economic way leads to the development of sustainable processes for the maintenance of information during the full lifecycle of an infrastructure asset which typically is $100+$ years. Documenting the information that is lost in the early stages of the project but could be valuable later aims to highlight the potential of GeoBIM as the linking mechanism among the different stages of the technical lifecycle.

This work explores whether the existence of GeoBIM from the early stages of the project will benefit the capture and maintenance of information in the long term, by integrating existing information produced from the BIM and GEO domains to serve operational AM. This in return, will enable data-driven processes which facilitate empowered, informed and costeffective decision making across the lifecycle.

Future research emphasizes on communicating the findings of this work by interviewing Asset Managers, as well as enhancing the proposed method of documenting loss of information. The proposed method can can be a starting point on initiating these discussions empowered by $3 \mathrm{D}$ visualization of potential information loss. This will help to raise awareness, highlight the importance of data integration and facilitate the collaboration between the Asset Managers and the Construction industry to showcase the potential of GeoBIM. 


\section{ACKNOWLEDGEMENTS}

The authors would like to acknowledge the contribution of Highways England, Skanska UK and Mott MacDonald for the data provision to support this research.

\section{REFERENCES}

ADMM, 2021. Asset Data Management Manual. https://www.standardsforhighways.co.uk/ha/standards/admm/ (20 May 2021).

Arroyo Ohori, K., Biljecki, F., Diakité, A., Krijnen, T., Ledoux, H., Stoter, J., 2017. Towards an integration of GIS and BIM data: what are the geometric and topological issues?. In: ISPRS Ann Photogramm, Remote Sens. Spatial Inf. Sci, Volume IV-4/W5, pp. 1-8. https://doi.org/10.5194/isprs-annals-IV-4-W5-1-2017.

Biljecki, F., Tauscher, H., 2019. Quality of bim-gis conversion. In: ISPRS Ann Photogramm, Remote Sens. Spatial Inf. Sci., Volume IV-4/8, pp. 35-42. https://doi.org/10.5194/isprs-annalsIV-4-W8-35-2019.

buildingSMART, 2021. Industry Foundation Classes (IFC). https://www.buildingsmart.org/standards/bsi-

standards/industry-foundation-classes/ (20 May 2021).

Boyes, G., Ellul, C., Irwin, D., 2017. Exploring BIM for Operational Integrated Asset Management - A Preliminary Study Utilising Real-world Infrastructure Data.

Ellul, C., Noardo, F., Harrie, L., and Stoter, J., 2020. The EuroSDR GeoBIM Project - Developing Case Studies For The Use Of GeoBIM In Practice. In Int. Arch. Photogramm. Remote Sens. Spatial Inf. Sci., XLIV-4/WI-2020, 33-40, https://doi.org/10.5194/isprs-archives-XLIV-4-W1-2020-332020, 2020.

Farghaly, K., Abanda, H., Vidalakis, C., Wood, G., 2017. BIM Big Data System Architecture for Asset Management: A Conceptual Framework. https://doi.org/10.24928/JC32017/0163.

Floros, G., Ruff, P., Ellul, C., 2020. Impact of Information Management during Design \& Construction on downstream BIM-GIS Interoperability for Rail Infrastructure. In ISPRS Ann Photogramm, Remote Sens. Spatial Inf. Sci., VI-4/W1-2020. 10.5194/isprs-annals-VI-4-W1-2020-61-2020.

Floros, G., Boyes, G., Owens, D., Ellul, C., 2019. Developing ifc for infrastructure: a case study of three highway entities. In ISPRS Ann Photogramm, Remote Sens. Spatial Inf. Sci., IV4/W8. 59-66. 10.5194/isprs-annals-IV-4-W8-59-2019.

Garramone, M., Moretti, N., Scaioni, M., Ellul, C., Re Cecconi, F., Dejaco, M.C., 2020. BIM and GIS Integration for Infrastructure Asset Management: a Bibliometric Analysis. In ISPRS Ann Photogramm, Remote Sens. Spatial Inf. Sci., Vol. 6, No. 4/W1, pp. 77-84.

Gelder, J., 2015. The principles of a classification system for BIM: Uniclass 2015. In 49th International Conference of the Architectural Science Association, 2015, pp.287-297.

ISO 55000:2014. Asset Management - Overview, Principles and Terminology.
Jafari, M., Parlikad, K., A., 2016. Challenges in Infrastructure Asset Management. In IFAC-PapersOnLine, Volume 49, Issue 28, 2016, Pages 185-190.

Kang, T.W., Hong, C.H., 2015. A study on software architecture for effective BIM/GIS-based facility management data integration. In Automation in Construction 54, 25-38. https://doi.org/10.1016/j.autcon.2015.03.019.

Liu, A.H., Ellul, C., Swiderska, M., 2021. Decision Making in the 4th Dimension-Exploring Use Cases and Technical Options for the Integration of 4D BIM and GIS during Construction. ISPRS International Journal of Geo-Information, 10(4), p.203. doi: http://dx.doi.org/10.3390/ijgi10040203.

Liu, X., Wang, X., Wright, G., Cheng, J.C.P., Li, X., Liu, R., 2017. A State-of-the-Art Review on the Integration of Building Information Modeling (BIM) and Geographic Information System (GIS). In ISPRS International Journal of GeoInformation 6, 53. https://doi.org/10.3390/ijgi6020053.

NBS, 2021. Uniclass 2015. https://www.thenbs.com/ourtools/uniclass-2015. (20 May 2021).

Noardo, F., Arroyo Ohori, K., Biljecki, F., Ellul, C., Harrie, L., Krijnen, T., Kokla, M., Stoter, J., 2020. The ISPRS-EUROSDR GEOBIM BENCHMARK 2019. In Int. Arch. Photogramm. Remote Sens. Spatial Inf. Sci., XLIII-B5-2020, 227-233, https://doi.org/10.5194/isprs-archives-XLIII-B5-2020-2272020, 2020.

Noardo, F., Harrie, L., Arroyo Ohori, K., Biljecki, F., Ellul, C., Eriksson, H., Guler, D., Hintz, D., Jadidi, M. A., Pla, M., Sanchez, S., Stouffs, R., Tekavec, J., Stoter, J., 2019. Tools for BIM-GIS Integration (IFC Georeferencing and Conversions): Results from the GeoBIM Benchmark 2019. In ISPRS International Journal of Geo-Information 9, 9.

PAS 1192-3. 2013. Specification for information management for the operational phase of assets using building information modelling. The British Standards Institution, 2013.

Park, T., Kang, T., Lee, Y., Seo, K., 2014. Project Cost Estimation of National Road in Preliminary Feasibility Stage Using BIM/GIS Platform. In Computing in civil and building engineering 8.

Shah, R., McMann, O., Borthwick, F., 2017. Challenges and prospects of applying asset management principles to highway maintenance: A case study of the UK. Transportation Research $\begin{array}{lllll}\text { Part } & \text { A } & 97 & \text { (2017), } & \text { 231-243. }\end{array}$ http://dx.doi.org/10.1016/j.tra.2017.01.011.

Sinha, C., K., Labi, S., Agbelie K., D., R., B., 2017. Transportation infrastructure asset management in the new millennium: continuing issues, and emerging challenges and opportunities, Transportmetrica A: Transport Science, 13:7, 591-606, DOI: 10.1080/23249935.2017.1308977.

Yang, Y., Ng, S.T., Xu, F.J., Skitmore, M., Zhou, S., 2019. Towards Resilient Civil Infrastructure Asset Management: An Information Elicitation and Analytical

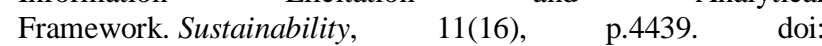
http://dx.doi.org/10.3390/su11164439. 